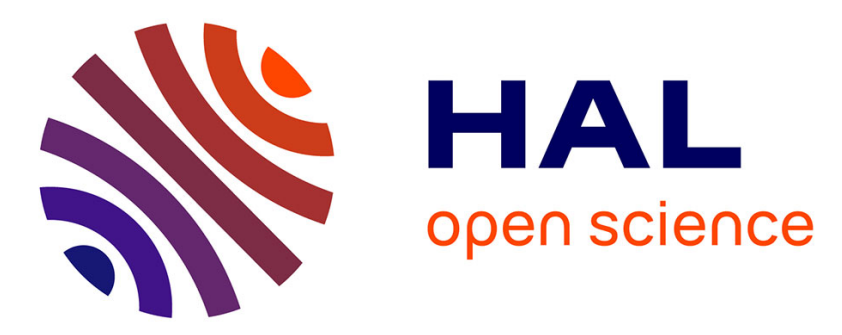

\title{
Email use in elementary school: An analysis of exchange patterns and content
}

Hans van Der Meij, Kerst Boersma

\section{To cite this version:}

Hans van Der Meij, Kerst Boersma. Email use in elementary school: An analysis of exchange patterns and content. British Journal of Educational Technology, 2002, 33(2), pp.189-200. 10.1111/14678535.00252 . hal-00190689

\section{HAL Id: hal-00190689 \\ https://telearn.archives-ouvertes.fr/hal-00190689}

Submitted on 23 Nov 2007

HAL is a multi-disciplinary open access archive for the deposit and dissemination of scientific research documents, whether they are published or not. The documents may come from teaching and research institutions in France or abroad, or from public or private research centers.
L'archive ouverte pluridisciplinaire HAL, est destinée au dépôt et à la diffusion de documents scientifiques de niveau recherche, publiés ou non, émanant des établissements d'enseignement et de recherche français ou étrangers, des laboratoires publics ou privés. 


\title{
E-mail use in elementary school: An analysis of exchange patterns and content
}

British Journal of Educational Technology, 2002, 33(2), 189-200

\begin{abstract}
Hans van der Meij and Kerst Boersma
In kidNET the authors, together with other researchers and teachers, examine the value of a new didactic approach for teaching biology and design \& technology in elementary school. E-mail and internet are functionally integrated into this plan (http://www.kidnet.utwente.nl/kidnet/). The project leader, Hans van der Meij, can be reached at: University of Twente, Faculty of Educational Science and Technology, P.O. Box 217, 7500 AE Enschede, The Netherlands; e-mail meij@edte.utwente.nl
\end{abstract}

\begin{abstract}
E-mail was embedded in a project in design \& technology education in elementary school. During four lessons children worked in groups on building a flying object. These groups communicated through e-mail with groups of children from another school. The analyses of the e-mails, as viewed from distributed cognition theory, focus on the exchange patterns and content.

Two characteristic exchange patterns are stacking and compounding. In stacking e-mails are sent out quickly enough to afford a 'just-in-time' exchange of information. In compounding the e-mails transcend lessons. An 'old' section of the e-mail reacts to the partner's e-mail about a previous lesson. A 'new' section deals with the current lesson.

Question-answer exchanges accounted for only about $15 \%$ of the communications. Connected discourse with explicit or implicit references to the partner's e-mail was likewise scarce. Groups mainly connected to each other through adoption, leading to shared scenarios of "We tell you our story - You tell us yours".

The conclusion discusses the impact of the task on the children's communication. Among others, a precise definition and teaming of the task is deemed necessary to favour embedded e-mail use. Because the genre of e-mail use in elementary school is yet to be defined the authors caution against imposing many constraints on what children write to each other.
\end{abstract}

\section{Introduction}

Mountaineers sometimes say that they climb mountains "because they are there". A similar statement appears to be true for computers in school. Teachers sometimes use computers in school because they are there. Just as in mountaineering, success in school does not come easily; there are many obstacles to overcome. Interestingly, most of these obstacles have little to do with the technology itself. Salomon (1995), among others, indicates that the success or failure of using computers in school largely depends on the orchestration of the various actors and factors in the whole learning environment.

We report here about a project on e-mail use by children from the upper grades of elementary school. The project employed e-mail as a tool to communicate about the lesson topic rather than as an issue in itself; e-mail was used as a means rather than an end. The main reason for employing e-mail as a tool in a real problem solving task directly relates to our conviction that such an approach improves domain-related learning and also affords better personalisations of the tool by the children. This conviction is in line with constructivist approaches to education.

The larger part of the preparations for the project involved creating a series of four lessons and lesson materials in which e-mail use formed an integrated, domain-related activity of the children. Developed in close collaboration with teachers, the lessons evolved around the problem of creating a flying object. Each lesson contained a prescribed e-mail moment. A teacher manual that supported the participants, detailed each lesson and suggested topics for the e-mail exchanges.

A critical element in the lesson plans involved teamwork because collaborative learning was deemed to be especially relevant for the relatively complex problem that the children were asked to solve (see Cohen, 1994; Dysthe, 1996; Mercer Wegerif and Dawson, 1999). The children were teamed up in small groups. During the various phases of problem solving these teams were to communicate about the project as a group, as part of the whole classroom, and as a conversational partner of a group of children from another school who worked on the 
same project. To facilitate the latter aspect, the teacher manual contained information about setting up an e-mail project with another school.

The results from the project were examined with two notions from distributed cognition theory in mind, namely the idea that information \& cognition is distributed and that learning objectives are (partly) defined by the learner (e.g., Cole \& Engeström, 1993; Dysthe, 1996; Mason, 1998; Pea, 1993).

The use of e-mail entails a distribution of information \& cognition in which time and space play a prominent role. E-mail affords an a-synchronous communication, meaning that there is always a time-lag between sending a message and receiving a reaction. This time-lag inevitably affects the uses of the tool. On the positive side it may stimulate reflection as children have more time to think through their responses. On the negative side it may reduce the chances of realising a truly connective discourse (versus "knowledge telling", see Scardamalia \& Bereiter, 1993) and getting a timely response to pressing questions.

E-mail use also affords communicating groups to bridge their distribution in space. In schools the factors that affect the success of such an enterprise include: (a) the proper (e.g., synchronous) scheduling of the lessons and their e-mail moments in the teamed-up classrooms, (b) creating a common ground for communication (e.g., by groups introducing themselves), and (c) the choice of an appropriate means of responding to an e-mail (e.g., by annotating, repeating or paraphrasing a portion of the received e-mail). Some of these issues are discussed when we present the results from analysing the content of the children's e-mails. In addition, we detail the exchange patterns that emerged. These patterns illustrate how the e-mails actually were distributed during the project.

E-mail is a lean medium. It is not much more than white space on a computer screen on which a message can be written. Apart from dictating a predominantly verbal form of communication, e-mail does not impose much structure on what gets communicated. In other words, e-mail gives children a great deal of freedom to personalise their communications. But there is no total freedom. The task is an important structuring factor and children are expected to communicate mainly about their design task. In addition, the teacher manual contained some suggestions for structuring the e-mails. Even so, it are the groups who determine how and what they communicate by and large. In other words, the objectives for the use of e-mail are defined by the children and the results thereof are illustrated with the findings of the analyses of the content of their communications.

\section{Method}

\section{Participants}

Sixteen elementary schools in the Netherlands participated in the project and data were gathered from 301 children with a mean age of 11 years. The children formed 87 groups that sent out a total of 214 e-mails. In preparing for the project, special attention was given to three top-5 obstacles to computer use in Dutch schools, namely: (a) lack of sufficient (and fast) computers, (b) insufficient knowledge and training support, and (c) lack of lesson materials containing an integrated computer component (Ten Brummelhuis \& Drent, 2000). The obstacle of computer access was handled by asking the participating schools to guarantee easy pupil access to the computer(s). The problem of technical know-how was circumvented by accepting only schools in which the participating teacher was a skilled e-mail user and by offering technical support upon request. The introduction already described how we handled the third obstacle.

\section{Coding and scoring}

An important aspect of the distributed nature of e-mail use transpires in the exchange patterns that emerge. These patterns are operationally defined as a mixture of the score for the exchange rate and participation rate for a group. The exchange rate measures the mean frequency of e-mails sent out by a group in a particular lesson. A rate of more than one e-mail is considered to be reasonably fast paced. The participation rate measures the continuity of the exchanges over the lesson series. A score of $75 \%$ indicates that a group has e-mailed its partner three out of the four lessons. Such a score also reflects a high level of participation.

Combining the low and high scores for exchange rate and participation rate yields four distinct exchange patterns. Figure 1 presents the criteria for these scores. Each distinct pattern is also given an appropriate name. For example, the exchange pattern of a group is characterized as incidental when the group sends out no more than one e-mail in a particular lesson and has e-mailed only during one or two of the four lessons. Chance alone favours the presence of the incidental and structural exchange pattern because of the interdependence of the exchange rate and participation rate. 
Figure 1: The exchange patterns that emerge from combining the scores for continuity in sending out e-mails in the four lessons (participation rate) with the scores for frequency of e-mails sent within lessons (exchange rate)

Coding of the content of e-mails followed a two-step procedure with segmentation preceding categorization. In segmentation, each e-mail is divided into meaningful units such as a principle sentence or a (subordinate) clause. Adding all the segments in an e-mail gives an impression of the mean volume of an e-mail.

In categorization, each segment is classified on four dimensions: (1) linguistic expression, (2) topic, (3) motivation and (4) connectivity. These dimensions and their subcategories were derived bottom-up as well as from theory. With regard to the later, only a few useful ideas could be abstracted from studies on e-mail exchanges (e.g., Atkinson-Christie, 1997; Duin \& Archee, 1996; McKeon, 1999; Williams \& Meredith, 1996). Our main source of inspiration was the work of Mercer (1996) on analysing face to face communications between children. A codebook was created to support the categorization by independent observers. Interobserver agreements yielded a satisfactory score of 0.66 (Cohen kappa) and higher for these codes.

Figure 2 illustrates the coding of two segments from an e-mail. Note that the Topic dimension is the only dimension in which the main categories are not mutually exclusive. Only here some segments can belong to two categories instead of just one. For example, the segment "We have a tip for you concerning the design of your aircraft" scores into the category Communication and in Domain Talk.

\section{INSERT FIGURE 2 HERE}

Figure 2: An illustration of a segmented and categorized e-mail

In scoring, the mean results for all groups were first calculated for individual lessons. These scores were later combined to create an overall picture of the content of the e-mails sent during the whole project. The tables that are presented in the next section now portray the 'average' e-mail for the average lesson.

\section{Results \& Discussion}

\section{Exchange patterns}

The incidental pattern dominated. On a total of 87 recorded e-mail groups, 56 groups $(64.4 \%)$ had more or less haphazard exchanges. The exchanges of yet another 17 groups followed a structural pattern. In this pattern the e-mails are relatively plentiful. An impressive $94 \%$ of these groups came from schools in which the children already regularly used e-mail before participating in the project.

The exchanges of 11 groups (12.6\%) fitted perfectly within a compound pattern. In this pattern each e-mail ideally consists of an 'old' section, in which the group reacts to a previous e-mail, and a 'new' section that provides the stimulus for its e-mail partner (see Figure 3).

\section{INSERT FIGURE 3 HERE}

Figure 3: In compounding, an e-mail ideally consists of two parts. One part deals with the last email from the partner group. In this Reaction the group reacts to issues from an earlier lesson. The second part is what the group would like to tell about their current situation. This Stimulus presents topics from the current lesson 
In a stacking pattern groups interact more than once between lessons. Information is now given and received 'just-in-time' because the children react quickly to the issues brought up by the e-mail partner. The exchanges of 3 groups (3.4\%) fitted this pattern (see Figure 4).

\section{INSERT FIGURE 4 HERE}

Figure 4: In stacking, e-mails are exchanged swiftly enough for groups to share views on current issues (i.e., the same lesson)

There was a statistically significant correlation between participation rate and exchange rate on the one hand, and e-mail volume on the other (respectively $\tau=0.40, \mathrm{p}<0.001$, and $\tau=0.69, \mathrm{p}<0.001$ ). Partial correlations with the effect of participation rate filtered out still showed a positive and statistically significant relationship between exchange rate and volume $\left(\tau_{\mathrm{xy} . \mathrm{z}}=0.56, \mathrm{p}<0.001\right)$. In other words, groups who sent out more e-mails also tended to make these e-mails longer. Perhaps this signals that e-mail functionality carries its own rewards. The reasoning could be like this: longer e-mails $\rightarrow$ are likely to carry more substance $\rightarrow$ which make the interaction more valuable $\rightarrow$ which help keep up participation.

\section{The content of the e-mails}

Dimension 1. Linguistic expression. The analyses in this dimension concentrated on three basic types of linguistic means: Statements, Questions and Responses. Statements are operationally defined as expressions that, unlike Questions, do not explicitly invite a reaction and that are also not clearly a reaction to a Question or a Statement from the partner. Reactions to a Question or Statement are classified as Responses.

Table 1: The mean appearance of a linguistic expression in an e-mail

\begin{tabular}{lcc}
\hline & Mean & Standard deviation \\
\hline Statements & 8.85 & 5.80 \\
Questions & 0.98 & 1.20 \\
Responses & 1.06 & 2.08 \\
\hline
\end{tabular}

Table 1 shows that the e-mails consisted mainly of Statements. Almost 9 of the 11 segments in the average email are Statements. The presence of Questions and Responses is about balanced and seems to suggest that groups discuss their partner's question(s) in their response. A detailed inspection of the data shows otherwise, however. Only 59\% of the Questions led to a Response. The remainder of the Responses were reactions to a Statement.

In speculating about the meaning of this finding some intriguing ideas can be advanced: (1) the reaction-inviting nature of questions (the 'illocuting force') is not as strong as people sometimes expect, (2) just as in face to face communications, it is not always necessary to ask a question to evoke a reaction, (3) it may not be wise to constrain the use of e-mail to an exchange of questions and answers. The latter idea addresses the rather widespread conception among lay people that e-mail is optimally suited for a swift exchange of questions and answers. The data indicate that this would have cut-off $85 \%$ of the communications if teachers would have allowed only for this type of exchange, all other things being equal. Perhaps more importantly, it would have deprived the groups from engaging in valuable social talk. Such talk about personally relevant issues helps build a relationship with the partner and contributes to creating a common ground (see Anderson and Guerrero, 1998; Baker, Hansen, Joiner and Traum, 1999).

Dimension 2. Topic. The topic dimension includes the categories of Communication, Social Talk and Domain Talk. Communication covers all segments in which the children say something about the process of communication. For example, a group may ask whether the other group has the ability to provide an answer to their question ("Do you know it?"), or it may express a desire to receive an answer ("We hope that you write back soon"). The category also contains expressions of an introductory nature such as "We have a question".

Social Talk includes 'chatter' about pop music, sports and the like. Within this category we also classified expressions about the children's preferences, knowledge and skills for school work (e.g., "I am good with computers"). 
Domain Talk covers all expressions about the domain of design \& technology. If e-mail is to serve its role as an important means for reflection, articulation and evaluation about the task at hand, the main body of an e-mail should probably fall within this category. The subcategories here are: context, goal or objective, result or evaluation, materials \& tools, planning and design principles.

Table 2: The mean appearance of a topical expression in an e-mail

\begin{tabular}{lcc}
\hline & Mean & Standard deviation \\
\hline Communication & 3.43 & 2.54 \\
Social Talk & 5.44 & 4.40 \\
Domain Talk & 5.58 & 1.61 \\
\hline
\end{tabular}

Table 2 indicates that Social talk and Domain Talk are found in about even proportions in the average e-mail. Compared to the total mean of 11 segments per e-mail, each comes close to a 50\%-score. Detailed examinations of the data revealed that the finding for Social Talk is inflated by a dominating presence in the first lesson. In this first e-mail groups introduced themselves, as one would expect. Because groups added very little other information, $74 \%$ of the segments in the first e-mail moment consisted of Social Talk.

From lesson two onwards there was much less Social Talk; the proportion of Social Talk for lesson 2, 3 and 4 was respectively 26\%, 23\% and 32\%. The proportion of Domain Talk increased rapidly after the first lesson and then remained stable and fairly high. For lesson 1, 2, 3 and 4 the scores were $17 \%, 46 \%, 53 \%$ and $44 \%$. In short, these findings reveal that there is a good deal of social talk but that this talk does not dominate the children's emails. In most e-mails the children are writing about task related matters.

Almost a third of the expressions deal with Communication. This seems to be just about the right amount. As in writing a letter, the children should follow certain formal rules of conduct, or 'netiquette' as these are called in email jargon. Like in any other form of communication there should also be room for such talk in e-mail exchanges.

Dimension 3. Motivation. This dimension consists of the categories Evaluation and Problem \& Trouble. Evaluation refers to all expressions containing a judgement or assessment. Judgements may relate to a situation, a product, or a personal characteristic. For example, a group might write "our group is cozy", or label an event as "funny". Evaluations could also involve the flying object, as in "Our plane did not go very far". Examples of Evaluation as an assessment of personal qualities or capacities are expressions such as "I am pretty good in many things in school" and "I know a lot about computers".

The category Problem \& Trouble contains a rather mixed variety of expressions that all share an implicit or explicit request for help or information. The subcategories here are expressions of ignorance and doubt and social conflict. Ignorance refers to segments such as "We just don't know what we should build" and "Do you have tips for us on this?" Expressions of ignorance say very little about what constitutes a satisfactory response. Expressions of doubt, in contrast, refer to a more clearly voiced uncertainty about what to do or think (e.g., "We do not know exactly how to insert the elastic"). Social conflict refers to a disagreement among group members, or between partner groups.

Table 3: The mean appearance of a motivational expression in an e-mail

\begin{tabular}{lcc}
\hline & Mean & Standard deviation \\
\hline Evaluation & 2.14 & 2.48 \\
Problem \& Trouble & 1.22 & 1.30 \\
\hline
\end{tabular}

Table 3 shows that Evaluations are found in $19 \%$ of the average e-mail and Problem \& Trouble in $11 \%$ of the cases. Apart from their apparent function as an outlet for certain emotions, both types of motivational expressions may be important for improving commitment. Expressed emotions such as feeling unsure or having a row, now become distributed and possibly shared. Thereby they may fortify the bond within and between groups.

Dimension 4. Connectivity. This dimension contains all expressions of interactivity or connected discourse. We distinguish three types: Connected Reactions, Unconnected Reactions, and Adoption. In a Connected Reaction the children explicitly refer to, or repeat, (part of) their partner's question or statement before reacting. A typical 
example is "The gas you asked about is called helium". E-mail programs have a reply feature to facilitate this type of connectivity, but none of the groups used this feature. All groups created their e-mails from scratch.

In an Unconnected Reaction groups respond to an expression without making this known explicitly. An example is the expression "The answer is four" which can be understood only within the context of an ongoing exchange. For the coding by the researchers this meant that the context had to be (re)constructed by consulting the e-mail of the corresponding group. For the receiving group of children an Unconnected Reaction is likewise incomprehensible unless the children consult the original e-mail, or remember the statement or question that triggered the response.

Adoption is an important and unique subcategory. It refers to expressions that are connected to each other by type similarity. In Adoption a group or child imitates a particular style or typology from another group or child. Among others, Adoption is found in introductory e-mails when group members use the same format for presenting themselves (e.g., "I am ... and my hobbies are ..."). To our knowledge, this format was spontaneously adopted by the other children in a group after being introduced by one of them. Adoption occurs within groups as well as across groups.

Table 4: The mean appearance of connective discourse in an e-mail

\begin{tabular}{lll}
\hline & Mean & Standard deviation \\
\hline Connected Reaction & 0.85 & 1.68 \\
Unconnected Reaction & 0.42 & 1.03 \\
Adoption & 4.26 & 7.73 \\
\hline
\end{tabular}

About one segment (9\%) of the average e-mail connects directly or indirectly to the e-mail topic of the partner group. The paucity of this aspect of connected discourse is compensated for by the presence of Adoption. Adoptions makes up 39\% of the average e-mail. The score for Adoption varies considerable for the four lessons. There is a preponderance in the first lesson with a $70 \%$ score, then a drop to $21 \%$ and $16 \%$ in the second and third lesson and an increase to $45 \%$ for the final lesson. When Adoption is used it typically leads to a series of emails that can be characterised as "We tell you our story - You tell us yours".

\section{Conclusion}

The important role of the task is stressed in several key notions from distributed cognition theory (e.g., Cole \& Engeström, 1993). Not surprisingly then, the task played a key role in the project. As indicated in the introduction, we chose to have children use e-mail as a tool as opposed to training them in the skills acquisition for e-mail use as an end in itself. For some children and groups this clearly led to some tension between the need to learn to use and the need to use. Often this problem was solved by mixing skilled and non-skilled children in a group so that the more experienced children could support the less experienced ones during their turn to work with e-mail. In this fashion e-mail was used in the way in which we think children are most likely to benefit from the experience, namely by embedding its use in solving a real task.

Distributed cognition theory also points to a strong impact of the task on teamwork. Among others, the task gives groups and group members a shared goal and perspective. The presence of a structural exchange pattern and findings on the topic of the e-mails and e-mail connectivity suggest that some of our efforts to create a shared (e.g., connected) discourse were successful. But looking back we think that the definition of the task for teaming up groups from different schools was not precise enough. That is, the project departed from the simple notion that the goal of creating a flying object would yield a sufficiently shared interest for the exchanges. It worked because, say, a balloon building group could communicate about general issues of design with an airplane building group. It would have been better, however, if we had teamed up groups who set out to create the same flying object. Then issues such as problem definition, choice of materials, and construction problems are even more likely to be really shared between groups.

Task factors also emerged in the differences that existed between the findings for the average e-mail, and the emails sent out during a particular lesson. Both the broader picture of the first and the detailed view of the latter were affected by task features. For example, what some teachers feared did not happen. The children did not use e-mail predominantly to chat about Madonna, soaps or hobbies. E-mail was used predominantly for task and domain-related purposes. In a similar vein, we think that not reducing e-mail usage to an exchange of questions and answers has had a positive effect on the communications. The link between a specific lesson, and hence task, 
and what gets communicated, most clearly transpires in the findings on the topic dimension. Among others the to-be-expected spike for social talk in the first communication is illustrative.

In conclusion, e-mail in school is not yet the integrated communication tool that it is in business settings. There is yet much to be studied and understood. There is yet a long way to go. We see the project as a first step towards defining the genre of e-mail use in elementary school (see Baron, 1998). But, just as in mountaineering, with the right equipment, motivation and endurance there are good chances for success.

\section{References}

Anderson P A and Guerrero L K (1998) Principles of communication and emotion in social interaction in Anderson P A and Guerrero L K (eds) Handbook of communication and emotion (pp. 49-96) Academic Press, San Diego, CA.

Atkinson-Christie A (1997) Using e-mail within a classroom based feminine pedagogy Journal of Research on Computing in Education 30 (2) 146-176.

Baker M J, Hansen T, Joiner R and Traum D (1999) The role of grounding in collaborative learning tasks in Dillenbourg P (ed) Collaborative learning. Cognitive and computational perspectives (pp. 31-63) Pergamon, Amsterdam.

Baron N S (1998) Letters by phone or speech by other means: the linguistics of e-mail Language \& Communication 18 133-170.

Cohen E G (1994) Restructuring the classroom: Conditions for productive small groups Review of Educational Research 64 (1) 1-35.

Cole M and Engeström Y (1993) A cultural-historical approach to distributed cognition in Salomon G (ed) Distributed cognitions. Psychological and educational considerations (pp. 1-46) Cambridge University Press, Cambridge, NY.

Duin A H and Archee R (1996) Collaboration via e-mail and internet relay chat: Understanding time and technology Technical Communication 43 (4) 402-412.

Dysthe O (1996) The multivoiced classroom Written Communication 13 (3) 385-425.

Mason L (1998) Sharing cognition to construct scientific knowledge in school context: The role of oral and written discourse Instructional Science 26 359-389.

McKeon C A (1999) The nature of children's e-mails in one classroom The Reading Teacher 52 (7) 698-706.

Mercer N (1996) The quality of talk in children's collaborative activity in the classroom Learning and Instruction 6 (4) 359-377.

Mercer N, Wegerif R and Dawson L (1999) Children's talk and the development of reasoning in the classroom British Educational Research Journal 25 (1) 95-111.

Pea R D (1993) Practices of distributed intelligence and designs for education in Salomon G (ed) Distributed cognitions. Psychological and educational considerations (pp. 47-87). Cambridge University Press, Cambridge, NY.

Salomon G (1995) What does the design of effective CSCL require and how do we study its effects? [On-line] Available: http://www-csc195.indiana.edu/csc195/outlook/62_Salomon.html

Scardamalia M and Bereiter C (1993). Technologies for knowledge-building discourse. Communications of the ACM 36 (3) 37-41

Ten Brummelhuis A and Drent M (2000) ICT-Monitor 1998-1999 basisonderwijs OCTO, Enschede.

Williams H L and Meredith E M (1996) On-line communication patterns of novice internet users Computers in the Schools 12 (3) 21-31. 


\begin{tabular}{|llll|}
\hline & & \multicolumn{2}{c|}{ Participation rate } \\
& & Low $(25 \%-50 \%)$ & High $(75 \%-100 \%)$ \\
Exchange rate & incidental & compounding \\
& High $(0-1)$ & stacking & structural \\
\hline
\end{tabular}

Figure 1: The exchange patterns that emerge from combining the scores for continuity in sending out e-mails in the four lessons (participation rate) with the scores for frequency of e-mails sent within lessons (exchange rate)

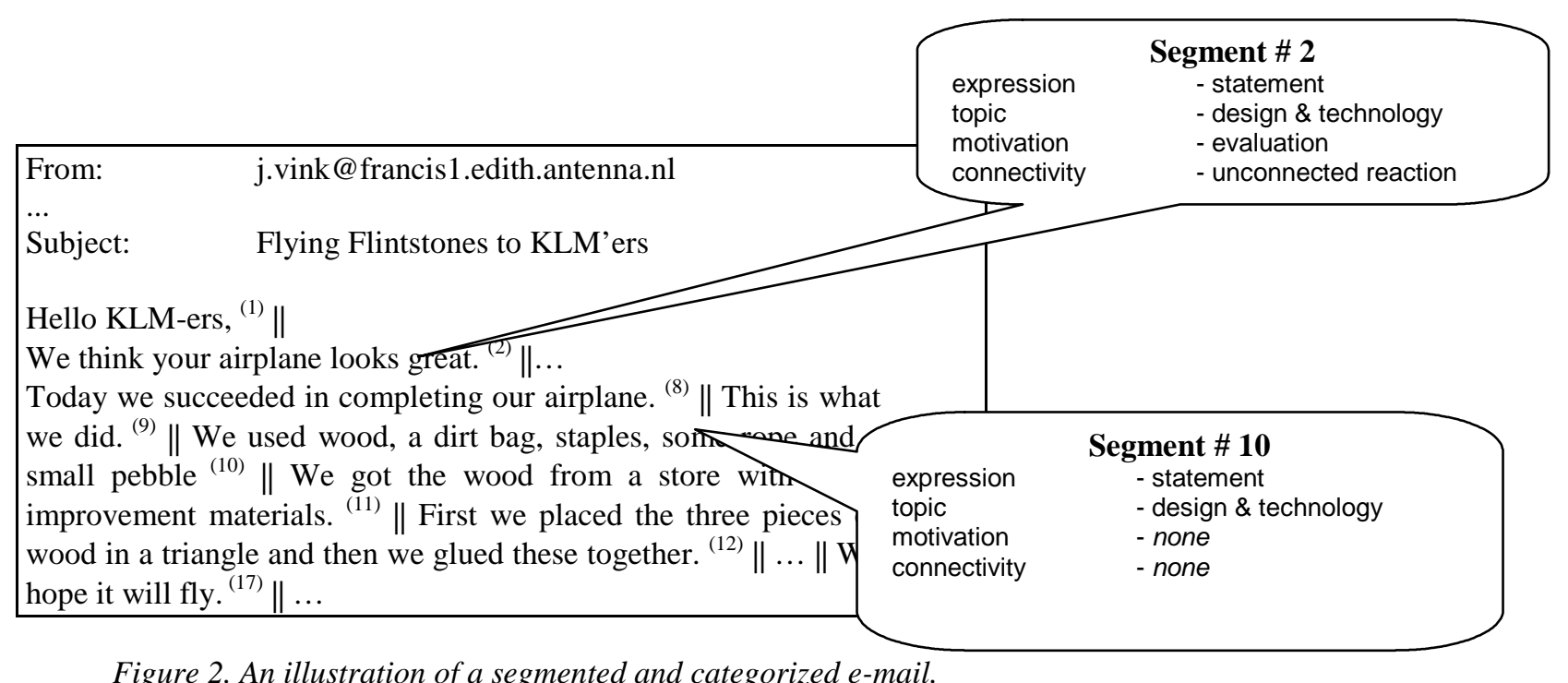

Figure 2. An illustration of a segmented and categorized e-mail.

Hi Airways and Stunt Flyers,

Thank your for your message. It was nice to hear that so many of you are playing volleyball. We too find Donald Duck a nice magazine.

Our design:

You have a bicycle pump and you place a cork on it with a coke bottle. Then you shoot the pump away. It was Gerjo's idea. According to Gerjo it will fly 50 meters. Yeah. Right. So, in a way it will be launched.

Stimulus

We hope that it will work and that the Flying Bottle will stay airborne for a long time. Perhaps you can use this.

Bye Interfly

Figure 3: In compounding, an e-mail ideally consists of two parts. One part deals with the last e-mail from the partner group. In this Reaction the group reacts to issues from an earlier lesson. The second part is what the group would like to tell about their current situation. This Stimulus presents topics from the current lesson 
Hello Space Invaders,

Yet get from us an answer to the question. You can best use a plastic bag. Reaction Attach strings to it and then fix the bag to the basket that you inflate. We hope that it works.

We have some questions for you too. We think our airplane might become Stimulus too heavy. Do you think we should use other, lighter materials? And do you know where we might get these?

Bye - bye the Daedalus

Hi Daedalus,

Use helium. We get it from John's father.

Space Invaders

Figure 4: In stacking, e-mails are exchanged swiftly enough for groups to share views on current issues (i.e., the same lesson) 